\title{
A Comparative Study on Effects of Neutral And Cold Underwater Massage on the Physiological Parameters of Healthy Individuals
}

\author{
Dr. Kanak Soni ${ }^{1}$, Dr. Prashanth Shetty ${ }^{2}$, Dr. Sujatha K.J. ${ }^{3}$ \\ ${ }^{I}$ (Department Of PG In Naturopathy, S.D.M College Of Naturopathy And Yogic Sciences, Ujire/ Rajiv Gandhi \\ University Of Health Sciences, Bangalore, India) \\ ${ }_{2}^{2}$ (Principal, S.D.M College Of Naturopathy And Yogic Sciences, Ujire/ Rajiv Gandhi University Of Health \\ Sciences, Bangalore, India) \\ ${ }^{3}$ (Dean, Division Of Natural Therapeutics, S.D.M College Of Naturopathy And Yogic Sciences, Ujire/ Rajiv \\ Gandhi University Of Health Sciences, Bangalore, India)
}

\begin{abstract}
:
Background and Objectives: Underwater massage has been reported to produce a significant number of physiological changes in blood pressure, heart rate variability, autonomic nervous system, and core temperature in young healthy subjects. The purpose of this study was to compare the impact on Regulatory response of Cardiovascular and Autonomic nervous system of neutral and cold underwater massage in healthy individuals.

Methodology: The subjects were students of the S.D.M. college of Naturopathy and Yogic Sciences, Ujire, Karnataka. They were randomly divided into two groups. According to the order in which they were recruited, they were allotted alternatively into two groups. Group-1: The neutral underwater massage group of 30 subjects and Group-2: The cold underwater massage group of 30 subjects. Subjects were assessed 5 minutes before and 5 minutes after the Neutral and Cold Underwater massage.

Results: The results have shown statistically significant increase in Heart rate ( $\leq \leq 0.001)$, respiration ( $p \leq 0.05)$, body temperature $(p \leq 0.001)$ and pulse $(p \leq 0.05)$ after neutral underwater massage during intervention period. Conclusion: The present study suggests that there was a statistically significant relationship between ANS activity manifested by heart rate variability and water temperatures. Neutral underwater massage enhances parasympathetic activity which can be a tool to calm down the mind and cold underwater massage enhances sympathetic activity which can be applied in cardiac health.
\end{abstract}

Keywords: Alternative and Complimentary Medicine, ANS, Heart Rate Variability, Hydrotherapy, Naturopathy, Neutral and Cold underwater massage.

\section{Introduction}

Water immersion has been reported to produce a significant number of physiological changes in blood pressure, heart rate variability (HRV), autonomic nervous System (ANS), and core temperature in young healthy subjects ${ }^{[1]}$ Hydrotherapeutic effects of bathing, which is achieved by heat and hydrostatic pressure, includes increasing perspiration and metabolism, alleviating muscle tension, fever and pain, and emotional suppression ${ }^{[2]}$ Various studies on the physiological effects of immersion bath, which include body temperature, blood pressure, intraocular pressure, regulation of autonomic nerve system and sleep, have been performed ${ }^{[3,4]}$ Regulatory response of cardiovascular and nervous system is changed by aging, and the changes of physiological parameters during immersion bath would be affected by the bath temperature and immersion body part ${ }^{[5-7]} \mathrm{We}$ would like to compare the changes of physiological parameters blood pressure, heart rate, internal body temperature and pulse- during neutral and cold underwater massage for young healthy individuals. Hydro therapy is one of the important parts of Naturopathy treatment, which has been proven beneficial in cardiovascular, hemodynamic, cellular immunity, psychological parameters and neonatal growth ${ }^{[8-11]}$ The hot and cold treatment modality has opposite effects on tissue metabolism, blood flow, Inflammation, edema and connective tissue extensibility ${ }^{[12]}$ The Neutral underwater massage is a procedure where warm water is given to body with mild pressure, which increases peripheral circulation. Hence, the purpose of this study was to compare the impact on Regulatory response of Cardiovascular and Autonomic nervous system of neutral and cold underwater massage in healthy individuals.

\section{Materials And Methods}

The study adopts Randomized Comparative Trial. This particular study has been conducted upon healthy human subjects who gave their consent for being included in this study. The subjects were selected and registered for study from S.D.M college of Naturopathy and yogic sciences, Dakshina Kannada, Karnataka (India). 60 Subjects were randomly allocated into two groups using computerized generated random number 
table.The neutral underwater massage group of 30 subjects and the Cold underwater massage group of 30 subjects.

The institutional ethical committee approval was obtained for conducting the study. For (group 1) neutral underwater massage was given for 20 minutes and for (group 2) cold underwater massage was given for 20 minutes. Assessments were done 5 minutes before and 5 minutes immediately after the intervention. The inclusion Criteria are the healthy students who are studying BNYS in SDMCNYS, UJIRE between 18 to 23 years, including males and females and who have given written informed consent. .

The Exclusion criteria are subject having any health disorders (in order to determine the health status of the subjects, in all cases a routine case history was taken and a routine clinical examination was conducted), who were taking medication which could influence autonomic function e.g., phenylpropanolamine as a common cold remedy, females during Menstrual Cycle and who are consuming alcohol and nicotine except caffeine. There were no dropouts during the study.

The subjects were seated on a chair recording leads were connected to the four-channel polygraph equipment (BIOPAC, Montana, USA; model No: BSL 4.0 MP 36) and monitored on a closed circuit TV. Instructions were given to the subjects to remain relatively undisturbed during the session.

In the underwater massage, the client lies relaxed in a large tub of water. The underwater massage apparatus constructed with tub, and directly connected with the sources of both hot and cold water, the connections being so arranged that the use of hot and cold water elsewhere in the bath-rooms not cause a variation of the temperature of the water delivered to the apparatus after it has once been adjusted for use. By means of a switch connecting the two valves so that they move together, water from either of these sets of pipes may be directed upon the patient with the same service hose. By this means the attendant has complete and instant control of both the temperature and the pressure in the administration of the underwater massage. A stream of water under pressure, (ranging from 0.5 to a maximum of 7.0 bar absolute pressure units), is applied by means of a hose that has interchangeable nozzles. The water needed for the massage is drawn from the tub and returned under pressure through the hose. An internal pump creates the high-pressure stream of water.

The massage programme starts with the effleurage, a soft stroking of muscles and connective tissue. During the following underwater massage 20 zones of the body (arranged in 10 groups) from the soles of the feet up to the shoulders are being treated with Max. pump water flow: 235 Litres/min by 12 water massage jets with performance control.

In Neutral underwater massage, $92-97^{0 \mathrm{~F}}\left(34-36^{0 \mathrm{C}}\right)$ water is made to flow in an underwater apparatus at controlled temperature and pressure. The subjects were asked to be in minimum dress and drink a glass of cold water before the treatment. Whereas, in Cold underwater massage, Water at a temperature of $45-65^{\mathrm{OF}}(8-$ $18^{0 \mathrm{C}}$ ) is made to flow in an underwater apparatus at controlled temperature and pressure. Same procedure followed as in neutral underwater massage.

Statistical analysis was performed using SPSS version 21.0 for windows. Data were expressed as mean \pm SD. Data were tested for variables. Repeated measures analysis of variance (ANOVA) followed by a post hoc analysis with Bonferroni adjustment for multiple comparisons between the mean values of both groups. Levels of significance were set to 0.05 .

\section{Results}

Table 1 Represents Kruskal-Wallis One-Way Analysis of Variance (Mann-Whitney U test value) for post inter-group comparisons and shows statistically significant increase in Heart rate $(\mathrm{p} \leq 0.001)$, respiration $(p \leq 0.05)$, body temperature $(p \leq 0.001)$ and pulse $(p \leq 0.05)$ after neutral underwater massage during intervention period.

A significant decrease in NN50 $(\mathrm{p} \leq 0.05)$, mean $\mathrm{RR}(\mathrm{p} \leq 0.05)$ and PNN50 and increased in RMSSD $(\mathrm{p} \leq 0.05)$, were also observed immediately following neutral underwater massage.

Figure 1 Represents the Changes in HR, RR, PR, RMSSD, NN50, pNN50, VLF, LF, HF, SBP, DBP, and TEMP., in post inter group comparison (Mann-Whitney U test). And figure 2 shows flow chart of trial profile.

\section{Discussion}

The present study suggests that there was a statistically significant relationship between ANS activity manifested by heart rate variability and water temperatures. Neutral underwater massage enhances parasympathetic activity which can be a tool to calm down the mind and cold underwater massage enhances sympathetic activity which can be applied in cardiac health. There were no adverse effects reported during or after the intervention. Cold underwater massage shown enhancement of better cardiac health than neutral underwater massage.

Comparing among two group's increase in HR $(\mathrm{p} \leq 0.001)$, respiration $(\mathrm{p} \leq 0.05)$, pulse $(\mathrm{p} \leq 0.05)$ and temperature $(\mathrm{p} \leq 0.001)$ Observed during neutral underwater massage. (Figure 1$)$ 
Reduction in heart rate and respiration following the cold underwater massage suggest sympathetic dominance which is in agreement with the study by Nagasawaet et al., ${ }^{[13]}$ Nishimura, M., \& Onodera, S. ${ }^{[14-15]}$ The probable mechanism of action might be peripheral vasodilatation following exposure to neutral temperature similar result was found by Sramek Pet al., ${ }^{[16]}$ Increase in surface temperature may signify peripheral vasodilatation and increase cutaneous circulation ${ }^{[17]}$

Pressure of the underwater massage in our study has shown little influence upon autonomic findings. The most important aspects in the underwater massage are found to be the temperature. The pressure of the underwater massage in the part of application produce a decided stinging sensation at each point of contact, a powerful reflex effect is produced by stimulation of the various sets of nerves which recognize temperature, pressure, pain, and tactile impressions hence various autonomic responses are given following underwater massage of varying temperature.

A rise in sympathovagal balance is associated with stress reduction, positive emotions, relaxation, and meditation: ${ }^{[18-20]}$ Such physiologic changes can cause decreases in cardiac irritability, blood pressure, and anxiety ${ }^{[21-23]}$

The main limitation of the study was that, it was not possible to record the assessments during the intervention to have a better understanding of the Physiology for comparison.

Directions for future research includes Observation duration can be increased up to 30 minutes, Conducting study with large sample size, Skin conductance (GSR) could be included, Study can be conducted on general population, Other variables can be included i.e. Myogram, Gastrogram, EEG etc.

Some strength giving criteria of the study are, there were no dropouts during the study. Subjects did not faced any problems during intervention or while collecting data. All the procedures were done in Ideal conditions and Qualitative results were collected, without any faults.

\section{Conclusion}

The present study suggest Neutral underwater massage enhances parasympathetic activity hence it can be applied effectively in treating stress, insomnia and anxiety, Whereas Application of cold underwater massage on autonomic function has enhancing role in sympathetic activity and commanding role in the cardiac tone .

\section{Acknowledgements}

We are thankful to all the volunteered students of SDM College of Naturopathy \& Yogic Sciences, Ujire, who had actively participated in our study. Regards to the statistician Dr.Vadiraja N. We are grateful to SDME Society, Ujire and Dr. Selva Kumar, RMO, SDM YOGA \& NATURE CURE HOSPITAL "SHANTIVANA", Dharmasthala, Karnataka, India for their required support to complete this study successfully.

\section{References}

[1]. Becker, B.E. (2009). Aquatic therapy: Scientific foundations and clinical rehabilitation applications. PMR, 1(9), 859-871.

[2]. F. B. Moor, Manual of Hydrotherapy and Massage. Idaho, USA: Pacific Press, 1964, ch 1.

[3]. A. Michalson, R. Rudtke, M. Buhring, G. Spahn, J. Langhorst and G. J. Dobos, "Thermal hydrotherapy improves quality of life and hemodynamic function in patients with chronic heart failure," American Heat Journal, vol. 146, pp.1-6, 2003.

[4]. W.-C. Liao, "Effects of passive body heating on body temperature and sleep regulation in the elderly: a systemic review," International Journal of Nursing Studies, vol. 39, pp. 803-810, 2002

[5]. L.B. Rowell, G. L. Brenglemann, and J. R. Blackman, " Redistribution of blood flow during sustained high skin temperature in resting man," J Applied Physiology, vol. 28, pp. 415-420, 1970

[6]. Y. Nagasawa, S. Komori, M. Sato, Y. Tsuboi, K. Umetani, Y. Watanabe, and K. Tamura, "Effects of hot bath immersion on autonomic activity and hemodynamics - Comparison of elderly patient and the healthy young," Japanese Circulation J, vol. 65, pp. 587-592, 2001

[7]. G.A. Thomas and E. R. William, "Comparison of responses of men to immersion in circulating water at 40.0 and $41.5^{\circ} \mathrm{C}$ " Aviat Space Environ Med, vol. 69, pp. 845-850, 1998.

[8]. W.N. Robiner. Psychological \& physical reactions to whirlpool baths. J Behav Med 1990;13(12):157-73

[9]. Zhao S, Xie L, Hu H, Xia J, Zhang W, Ye N, Chen B. A study of neonatal swimming (water therapy) applied in clinical obstetrics. J Matern Fetal Neonatal Med 2005;17(1):59-62.

[10]. Scott Nadler F, Kurt Weingand, Roger Kruse J. The Physiologic Basis and Clinical Applications of Cryotherapy and Thermotherapy for the Pain Practitioner. Pain Physician 2004;(7):395-99.

[11]. Ryan Bradley, Karen J Sherman, Sheryl Catz, Carlo Calabrese, Erica B Oberg, Luesa Jordan Lou Grothaus, Dan Cherkin. Adjunctive naturopathic care for type-2 diabetes: patient reported and clinical outcomes after one year. BMC Complementary and Alternative Medicine 2012;12:44.

[12]. YoshinaoNagashima, MichihitoIgaki, Atsushi Suzuki, Shuichi Tsuchiya, Yoshimi Yamazaki, Michiko Hishinuma, Sachiko Oh-ishi, MasatakaMajima. Application of a Heat- and Steam-Generating Sheet Increases Peripheral Blood Flow and Induces Parasympathetic Predominance. Evidence-Based Complementary and Alternative Medicine 2011;(13):1-13.

[13]. Nagasawa, Y., Komori, S., Sato, M., Tsuboi, Y., Umetani, K., Watanabe, Y., et al. Effects of hot bath immersion on autonomic activity and hemodynamics: Comparison of the elderly patient and the healthy young. Japanese Circulation Journal, 2001; 65(7), 587-592.

[14]. Nishimura, M., \& Onodera, S. Effects of supine floating on heart rate, blood pressure and cardiac autonomic nervous system activity. Journal of Gravitational Physiology, 2000;7(2), 171-172. 
[15]. Nishimura, M., \& Onodera, S. Effects of water temperature on cardiac autonomic nervous system modulation during supine floating. Journal of Gravitational Physiology, 2001; 8(1), 65-66.

[16]. Sramek P, Simeckova M, Jansky L, SavlikovaJ,Vybiral S,. Human physiological responses to immersion into water of different temperature Eur J ApplPhysiol; 2000; 81950: 436-42.

[17]. Becker BE, Hildenbrand k, whitcomb RK, Sanders JP.Biophsiologic effect of warm water immersion. International Journal of Aquatic Research and Education, 2009; 3(1),. 24-37. European Journal of Applied Physiology \& Occupational Physiology 1995 , Volume 71,issue5,pp431-438 http://link.springer.com/article/10.1007/BF00635877\#page-1.

[18]. Thayer, R.E., Newman, J.R., \& McClain, T.M. (1994). Self-regulation of mood: Strategies for changing a bad mood, raising energy, and reducing tension. Journal of Personality and Social Psychology, 67(5), 910-925.

[19]. Thayer, J.F., \& Lane, R.D. (2000). A model of neurovisceral integration in emotion regulation and dysregulation. Journal of Affective Disorders, 61(3), 201-216.

[20]. Thayer, J.F., \& Siegle, G.J. (2002). Neurovisceral integration in cardiac and emotional regulation. IEEE Engineering in Medicine and Biology Magazine, 21(4), 24-29.

[21]. Thayer, J.F., \& Brosschot, J.F. (2005). Psychosomatics and psychopathology: Looking up and down from the brain. Psychoneuroendocrinology, 30(10), 1050- 1058.

[22]. Thayer, J.F., \& Sternberg, E. (2006). Beyond heart rate variability: Vagal regulation of allostatic systems. Annals of the New York Academy of Sciences, 1088, 361-372.

[23]. Thayer, J.F., \& Lane, R.D. (2007). The role of vagal function in the risk for cardiovascular disease and mortality. Biological Psychology, 74(2), 224-242.

Figure 1 Represents the Changes in HR, RR, PR, RMSSD, NN50, pNN50, VLF, LF, HF, SBP, DBP, and TEMP., in post inter group comparison (Mann-Whitney U test).

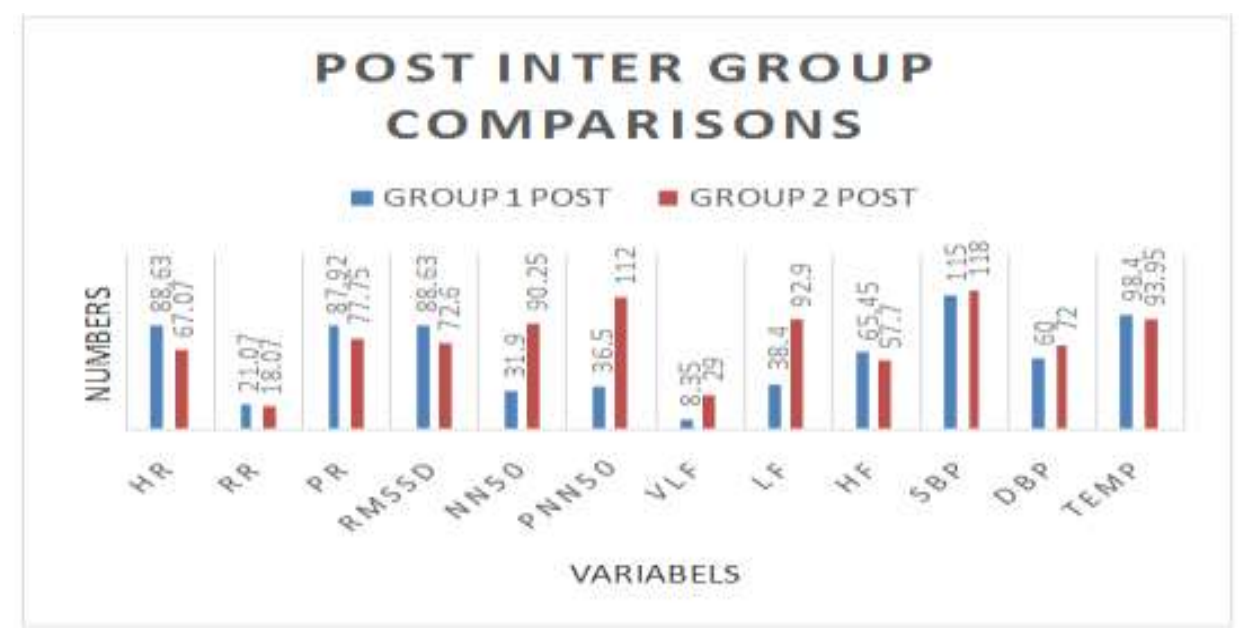

FIGURE 2 Flow chart of TRIAL PROFILE.

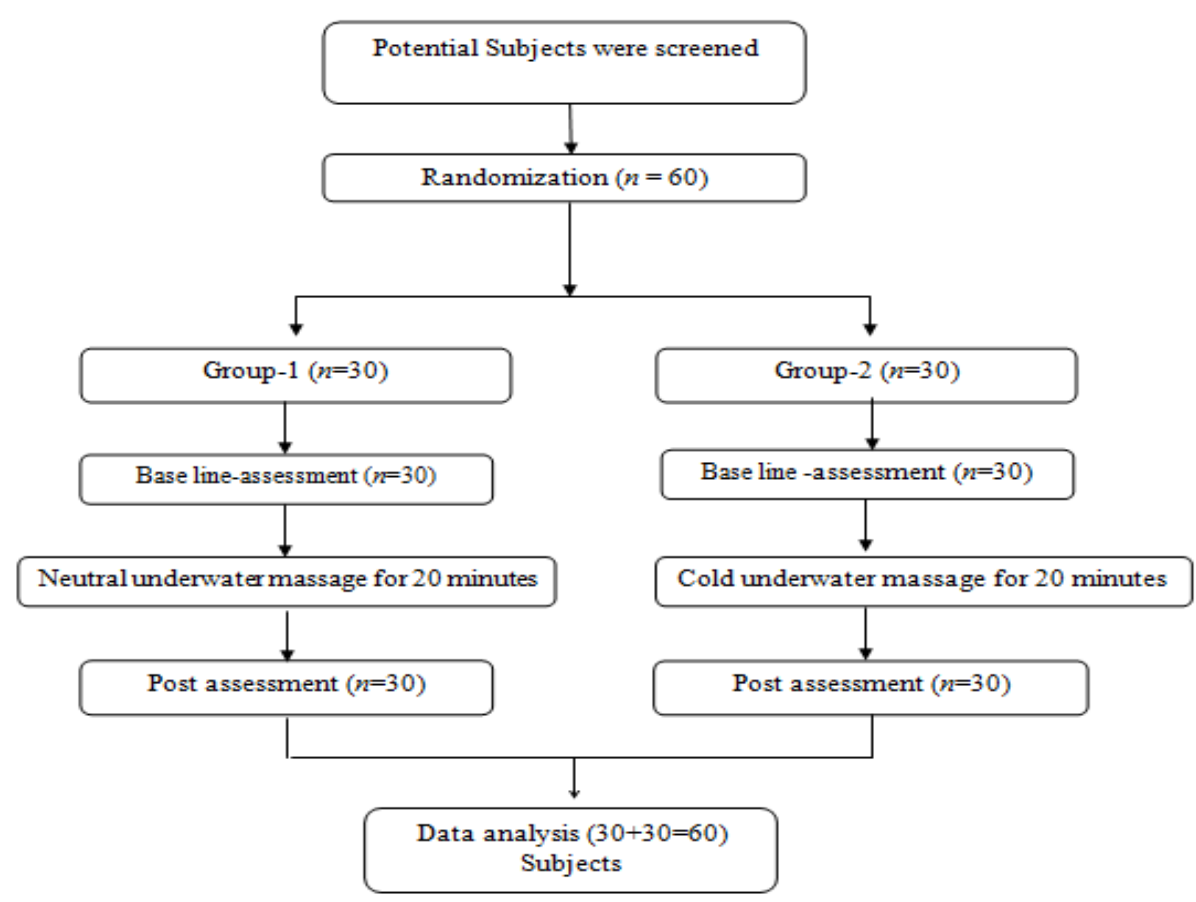


Table 1 Represents Kruskal-Wallis One-Way Analysis of Variance (Mann-Whitney U test value) for post inter-group comparisons and shows statistically significant increase in Heart rate $(\mathrm{p} \leq 0.001)$, respiration $(\mathrm{p} \leq 0.05)$, body temperature $(\mathrm{p} \leq 0.001)$ and pulse $(\mathrm{p} \leq 0.05)$ after neutral underwater massage during intervention period.

\begin{tabular}{|l|l|l|l|l|}
\hline $\begin{array}{l}\text { VARIABLE( } \\
\text { Post } \\
\text { variables) }\end{array}$ & $\begin{array}{l}\text { GROUP 1 } \\
\text { (NUWM) } \\
\text { Sample } \\
\text { median (SD) }\end{array}$ & $\begin{array}{l}\text { GROUP 2 } \\
\text { (CUWM) } \\
\text { Sample } \\
\text { median(SD) }\end{array}$ & $\begin{array}{l}\text { Mann- } \\
\text { Vhitney U } \\
\text { test values }\end{array}$ & $\begin{array}{l}\text { P- } \\
\text { VALUE }\end{array}$ \\
\hline MEAN HR & $88.63(8.51)$ & $67.07(9.58)$ & 841.00 & $0.00^{*}$ \\
\hline RR & $21.07(3.16)$ & $18.07(2.49)$ & 748.00 & $0.00^{*}$ \\
\hline PULSE(PR) & $87.92(8.49)$ & $77.75(7.69)$ & 730.00 & $0.00^{*}$ \\
\hline MEAN RR & $680.65(70.4)$ & $811.75(217.2)$ & 223.00 & $0.00^{*}$ \\
\hline RMSSD & $88.63(8.48)$ & $72.60(17.74)$ & 123.50 & $0.00^{*}$ \\
\hline NNS0 & $31.90(37.25)$ & $90.25(49.28)$ & 164.00 & $0.00^{*}$ \\
\hline PNN50 & $36.50(61.04)$ & $112.00(64.82)$ & 155.00 & $0.00^{*}$ \\
\hline VLF & $8.35(14.86)$ & $29.00(21.85)$ & 581.50 & $0.05^{*}$ \\
\hline LF & $38.40(16.05)$ & $92.90(32.71)$ & 514.00 & 0.34 \\
\hline HF & $65.45(18.34)$ & $57.70(19.04)$ & 408.00 & 0.53 \\
\hline LF/HF & $35.30(18.32)$ & $40.05(19.62)$ & 512.00 & 0.36 \\
\hline SBP & $115.00(10.3)$ & $118.00(12.67)$ & 495.50 & 0.50 \\
\hline DBP & $60.00(6.97)$ & $72.00(8.43)$ & 131.00 & $0.00^{*}$ \\
\hline TEMP & $98.40(0.81)$ & $93.95(1.17)$ & 897.00 & $0.00^{*}$ \\
\hline
\end{tabular}

